\title{
Aclidinium improves exercise endurance, dyspnea, lung hyperinflation, and physical activity in patients with COPD: a randomized, placebo-controlled, crossover trial
}

Kai M Beeh ${ }^{1 \dagger}{ }^{\dagger}$ Henrik Watz $^{2 \dagger}$, Luis Puente-Maestu ${ }^{3}$, Luis de Teresa ${ }^{4}$, Diana Jarreta ${ }^{5}$, Cynthia Caracta ${ }^{6}$, Esther Garcia Gil ${ }^{5}$ and Helgo Magnussen ${ }^{2 *}$

\begin{abstract}
Background: This study evaluated the effects of aclidinium bromide, a long-acting muscarinic antagonist indicated for maintenance treatment of chronic obstructive pulmonary disease (COPD), on exercise endurance, dyspnea, lung hyperinflation, and physical activity.

Methods: In this randomized, double-blind, crossover study, patients with stable COPD and moderate-to-severe airflow limitation received aclidinium $400 \mu \mathrm{g}$ twice daily or placebo via Genuair/Pressair ${ }^{\oplus a}$ for 3 weeks (2-week washout between treatment periods). The primary endpoint was change from baseline to Week 3 in endurance time, measured by constant work rate cycle ergometry testing at 75\% peak incremental work rate. Changes from baseline in intensity of exertional dyspnea (Borg CR10 Scale ${ }^{\oplus}$ ) and trough inspiratory capacity were secondary endpoints. Additional endpoints included changes from baseline in other spirometric, plethysmographic, and physical activity (assessed by objective accelerometer measurement) parameters. Efficacy endpoints were analyzed using an analysis of covariance model.
\end{abstract}

Results: In total, 112 patients were randomized and treated (mean age 60.3 years; mean post-bronchodilator forced expiratory volume in $1 \mathrm{~s} 1.7 \mathrm{~L}$ [56.7\% predicted]; mean endurance time $485.7 \mathrm{~s}$ ). After 3 weeks, endurance time was significantly increased with aclidinium versus placebo (treatment difference $58.5 \mathrm{~s} ; \mathrm{p}<0.05$ ). At Week 3 , aclidinium significantly reduced dyspnea intensity at isotime during exercise (treatment difference $-0.63 ; p<0.05$ ) and improved trough inspiratory capacity (treatment difference $78 \mathrm{~mL} ; \mathrm{p}<0.05$ ) versus placebo. Significant improvements in spirometric, plethysmographic, and some physical activity parameters were observed with aclidinium versus placebo.

Conclusions: These results suggest that aclidinium significantly improves exercise endurance, exertional dyspnea, hyperinflation, and physical activity in patients with COPD.

Trial registration: ClinicalTrials.gov identifier: NCT01471171; URL: www.clinicaltrials.gov.

Keywords: Aclidinium, COPD, Exercise endurance, Long-acting muscarinic antagonists, Physical activity

\footnotetext{
* Correspondence: magnussen@pulmoresearch.de

${ }^{\dagger}$ Equal contributors

2Pulmonary Research Institute at LungClinic Grosshansdorf, Airway Research

Centre North, German Centre for Lung Research, Woehrendamm 80,

D-22927 Grosshansdorf, Germany

Full list of author information is available at the end of the article
} 


\section{Background}

Exercise limitation, driven predominantly by activity-related dyspnea, is an important feature of chronic obstructive pulmonary disease (COPD) that compromises daily living activities, leads to physical deconditioning, and contributes to a reduced perceived quality of life [1-6]. Lung hyperinflation is thought to represent a mechanical link between the characteristic expiratory airflow impairment, dyspnea, and exercise capacity $[5,6]$.

In patients with COPD, expiratory flow limitation and reduced lung elastic recoil result in air trapping and an increased end-expiratory lung volume (EELV) compared with healthy individuals [5-8]. During physical activity, acute increases in EELV (dynamic hyperinflation) occur and dyspnea is exacerbated, which can lead to avoidance of activity [5-8]. Alleviating hyperinflation and improving dyspnea, exercise tolerance, and levels of physical activity are important therapeutic goals in the management of COPD [9].

While there is a large body of clinical evidence regarding the effect of long-acting bronchodilators, including long-acting muscarinic antagonists (LAMAs), on exercise endurance [10-13], little is known about the translation of such improvements into changes in everyday physical activity. Aclidinium bromide is a novel LAMA recently approved, at a dose of $400 \mu \mathrm{g}$ twice daily (BID), as a treatment for COPD [14,15]. In a previous study, aclidinium $200 \mu \mathrm{g}$ once daily (QD) significantly improved exercise endurance time, exertional dyspnea, and static hyperinflation versus placebo in patients with COPD [16]. Here we report results from a randomized, double-blind Phase IIIb crossover study to evaluate the effect of aclidinium $400 \mu \mathrm{g}$ BID on cycling exercise endurance, exertional dyspnea, and lung hyperinflation in patients with COPD. A thorough profiling of lung volumes and objective measures of daily physical activity are also included.

\section{Methods}

\section{Study design and treatment}

This Phase IIIb randomized, double-blind, crossover study was conducted between November 2011 and June 2012 at 14 sites in Germany, Spain, and the UK (clinicaltrials.gov identifier: NCT01471171). Following screening and a 2- to 3 -week run-in period (including a visit 1 week before Visit 1 to familiarize patients with study procedures), patients were randomized (1:1; Visit 1) to aclidinium $400 \mu \mathrm{g}$ (metered dose; equivalent to aclidinium $322 \mu \mathrm{g}$ delivered dose) BID or placebo, each for 3 weeks in one of two sequences, with a 2-week washout between treatments (Figure 1).

Aclidinium and matched placebo were administered BID (09:00 $\pm 1 \mathrm{~h}$ and 21:00 $\pm 1 \mathrm{~h}$ ) via a dry powder inhaler $\left(\right.$ Genuair $^{\circ} /$ Pressair $\left.^{\circ \mathrm{a}}\right)$. Randomization was performed according to unique patient identification numbers and a computer-generated random allocation sequence; patients and investigators were blinded to treatment allocation throughout the study.

Treatment with other long-acting bronchodilators was not permitted during the study. Patients were required to have discontinued treatment with LAMAs at least 7 days prior to the screening visit. Treatment with long-acting $\beta_{2}$-agonists (LABAs) must have been discontinued at least $48 \mathrm{~h}$ prior to screening for BID LABAs and at least 7 days prior to screening for QD LABAs. Relief medication (salbutamol pressurized metered dose inhaler $100 \mu \mathrm{g} / \mathrm{puff}$ ) was provided for symptom control as needed (except $\leq 6 \mathrm{~h}$ prior to lung function testing at each visit). The following maintenance therapies were also permitted if their use had been stable for $\geq 4$ weeks prior to study entry: oral sustainedrelease theophylline, inhaled corticosteroids, and oral or parenteral corticosteroids (prednisone $\leq 10 \mathrm{mg}$ per day or $\leq 20 \mathrm{mg}$ every other day). Corticosteroid use was required to be suspended for $\geq 6 \mathrm{~h}$ prior to lung function testing at any visit.

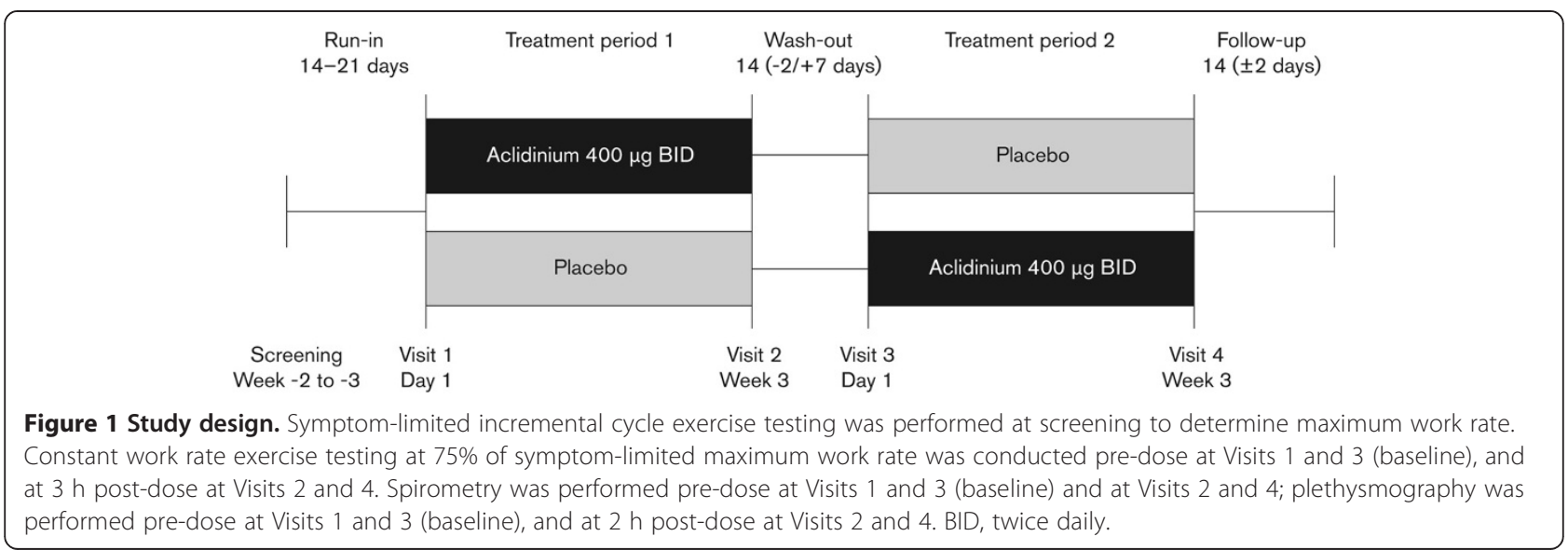




\section{Study population}

Patients aged $\geq 40$ years with stable COPD and moderateto-severe airflow limitation (post-bronchodilator forced expiratory volume in $1 \mathrm{~s}\left[\mathrm{FEV}_{1}\right] \geq 30 \%$ and $<80 \%$ of the predicted value, and $\mathrm{FEV}_{1} /$ forced vital capacity [FVC] $<70 \%$ at screening [9]), who were current or former cigarette smokers (smoking history of $\geq 10$ pack-years) and had a functional residual capacity (FRC) of $\geq 120 \%$ of the predicted value at screening were eligible. Severity of dyspnea was not a specific inclusion criterion in the study.

Patients with a history of asthma, or any other clinically significant respiratory, cardiovascular or other systemic condition that may have contributed to dyspnea and exercise limitation, were not eligible to participate. Additional exclusion criteria included a respiratory tract infection or COPD exacerbation within 6 weeks prior to screening (within 3 months if exacerbation resulted in hospitalization), a requirement for long-term oxygen therapy ( $\geq 15 \mathrm{~h} /$ day), an inability to use the study inhaler, and contraindications for either the use of anticholinergic drugs or cardiopulmonary exercise testing [17]. Patients who, in the investigator's opinion, may have needed to start a pulmonary rehabilitation program during the study and/or patients who started/finished a pulmonary rehabilitation program within 3 months prior to the screening visit were also excluded.

A symptom-limited incremental cycle exercise test was performed at screening to determine the maximum work rate that patients were able to maintain for $\geq 30 \mathrm{~s}$. Patients who cycled $<2 \mathrm{~min}$ or $>20 \mathrm{~min}$ during exercise testing at $75 \%$ of maximum work rate during the run-in visit or Visit 1 (pre-randomization) were not permitted to continue in the study.

Patients could be discontinued from the study at any time at their own request or in the event of ineligibility, non-compliance, lack of efficacy, loss to follow-up (nonattendance), safety concerns (including moderate or severe COPD exacerbation), or any other reason at the investigator's discretion.

The study was approved by the Independent Ethics Committees at each site (see Additional file 1) and was conducted in accordance with the Declaration of Helsinki, International Conference on Harmonisation, and Good Clinical Practice. Patients provided written informed consent before participating in any study procedures.

\section{Study assessments and endpoints}

Constant work rate cycle ergometry testing at $75 \%$ maximum work rate was conducted pre-dose at Day 1 (baseline) of each treatment period (Visits 1 and 3), and at $3 \mathrm{~h}$ post-dose at Week 3 of each period (Visits 2 and 4). This consisted of 3 min rest followed by 3 min unloaded cycling before the constant phase, in which work rate was increased to $75 \%$ of maximum work rate and patients were encouraged to maintain a pedaling rate of 50-70 rotations per min until symptom limitation. Change from baseline in exercise endurance time (time from the start of the loaded test to the point of symptom limitation) to Week 3 was the primary endpoint.

Before exercise, every $2 \mathrm{~min}$ during, and at the end of exercise, patients rated the intensity of their dyspnea using the Borg CR10 Scale ${ }^{\bullet}$ (perceived exertion, range: $0=$ 'nothing at all' to $10=$ 'extremely strong/maximal'). If patients considered the intensity of their dyspnea to be stronger than 'extremely strong/maximal', they could use a larger numerical value ('absolute maximum'). During exercise, inspiratory capacity (IC) was measured spirometrically at the same time points as a marker of dynamic hyperinflation. Change from baseline to Week 3 in intensity of dyspnea at isotime (duration of the shortest exercise test during Visits 1, 2, 3, and 4) was a secondary study endpoint. Changes from baseline to Week 3 in IC before exercise, every $2 \mathrm{~min}$ during exercise, at isotime, and at the end of exercise were additional endpoints. EELV at rest, at isotime, and at the end of exercise was calculated post-hoc by subtracting IC at each time point from mean total lung capacity (TLC) at $2 \mathrm{~h}$ post-dose. Oxygen saturation $\left(\mathrm{SpO}_{2}\right)$ during exercise was assessed using a pulse oximeter.

Change from baseline in resting IC at Week 3 was also a secondary endpoint. Resting IC was assessed spirometrically pre-dose (trough) at each visit, according to American Thoracic Society and European Respiratory Society guidelines [18,19]. Changes from baseline at Week 3 in trough $\mathrm{FEV}_{1}$ and FVC were also measured. All spirometry data were transferred for centralized reading and underwent a two-step quality-control process. Resting FRC, residual volume (RV), TLC, and specific airway conductance (sGaw) were assessed by whole-body plethysmography, performed pre-dose on Day 1 of each treatment period, and pre-dose and at $2 \mathrm{~h}$ post-dose at Week 3 of each period.

To assess physical activity, patients wore an armband device (SenseWear Pro3 ${ }^{\circ}$, BodyMedia Inc., Pittsburgh, PA, USA) day and night (excluding time spent for personal hygiene purposes) for 7 days prior to the start of, and during the last week of, each treatment period. Changes from baseline in steps per day, minutes of at least moderate activity ( $>3$ metabolic equivalents) per day, mean daily active energy expenditure $>3$ metabolic equivalents (kcal per day), and mean physical activity level (PAL; total energy expenditure divided by resting energy expenditure) [20] at Week 3 were additional efficacy endpoints. Baseline PAL values were also used to categorize patients as 'extremely inactive' (PAL <1.40), 'sedentary' (PAL 1.40-1.69), and 'at least moderately active' (PAL $>1.70)$ [20]. The frequency of nocturnal awakenings due to COPD symptoms and 
relief medication use were also recorded daily using patient diaries.

Safety assessments included monitoring of adverse events (AEs) throughout the study, laboratory assessments at screening and Visit 4, and physical examination, blood pressure measurement, and 12-lead electrocardiogram at screening and at Visits 1 and 4.

\section{Statistical analysis}

A population of 84 patients was estimated to provide $>85 \%$ power to detect a treatment group difference of $120 \mathrm{~s}$ for the primary endpoint. The study, therefore, planned to screen 170 patients and to randomize 110 patients, allowing for a $35 \%$ screening failure rate and a $20 \%$ drop-out rate.

Analyses of efficacy variables were performed on the intent-to-treat (ITT) population (all randomized patients who took $\geq 1$ dose of study drug and had $\geq 1$ baseline and post-dose assessment for the primary endpoint in $\geq 1$ of the two treatment periods). Efficacy endpoints were analyzed using an analysis of covariance model with treatment and period as fixed effects, patients as a random effect, and baseline values as covariates. Least squares means and 95\% confidence intervals $(\mathrm{CI})$ were calculated for treatment group differences $(\Delta)$. Adjustment for multiplicity was performed using a step-down approach: if the comparison between aclidinium and placebo for the primary endpoint (exercise endurance time) was significant at the 5\% level, then the secondary endpoints were tested in turn (trough IC first, intensity of dyspnea at isotime second). EELV at baseline and at Week 3 was analyzed descriptively. Only patients with $\geq 5$ days with $\geq 22 \mathrm{~h}$ valid data were included in the analysis of physical activity parameters [20].

Post-hoc analyses were performed to investigate the relationship between changes from baseline in endurance time and physical activity, and between changes from baseline in endurance time and lung volumes (Pearson Correlation Coefficients). In addition, changes from baseline in endurance time and trough IC at Week 3, and physical activity endpoints over the last week of treatment, were assessed according to baseline PAL. Analyses were performed using an analysis of covariance model with treatment and period as fixed effects, patients as a random effect, and baseline values as covariates.

Patient demographic and baseline characteristics, and safety outcomes, were summarized descriptively based on the safety population (all randomized patients who took $\geq 1$ dose of study drug).

\section{Results}

\section{Study population}

Of 149 patients screened, 112 were randomized and treated (safety analysis population) and 110 were included in the ITT population (Figure 2). The study was completed by 106 patients; 6 patients discontinued due to AEs.
Patient demographics and baseline characteristics are summarized in Table 1. Details of prior COPD medication use are shown in Additional file 2. Pre-dose at Visit 1, 49 patients $(44.5 \%)$ in the ITT population developed dynamic hyperinflation during exercise (defined as a $>150 \mathrm{~mL}$ decrease from rest in IC [21]).

\section{Efficacy endpoints \\ Exercise endurance, exertional dyspnea, and dynamic hyperinflation}

After 3 weeks of treatment, change from baseline in exercise endurance time was significantly greater with aclidinium compared with placebo $(\Delta=58.5 \mathrm{~s} ; 95 \%$ CI 9.0, 108.0; $\mathrm{p}<0.05$; Figure 3). The percentage change from baseline was $9.3 \%$ with placebo and $18.2 \%$ with aclidinium at Week 3.

Compared with placebo, aclidinium also significantly reduced the intensity of dyspnea at isotime from baseline to Week $3(\Delta=-0.63$; 95\% CI $-1.11,-0.14 ; \mathrm{p}<0.05)$ and significantly improved dynamic IC from baseline at Week 3 when measured before exercise, at isotime, and at the end of exercise (Figure 4). With aclidinium treatment, improvements from baseline in IC were seen for every 2-min interval during the first $10 \mathrm{~min}$ of exercise at Week 3 (range: $79 \mathrm{~mL}$ to $132 \mathrm{~mL}$; Additional file 3). In contrast, IC decreased compared with baseline for each corresponding period in the placebo group (range $-16 \mathrm{~mL}$ to $-110 \mathrm{~mL}$; Additional file 3). Aclidinium significantly improved IC compared with placebo at each interval from 0 to $8 \mathrm{~min}$; there was no significant difference at 8-10 min. Consistent with improvements in dynamic IC, EELV at Week 3 was also reduced compared with baseline during exercise with aclidinium $400 \mu \mathrm{g}$ BID (Figure 5). Reductions in EELV were observed at rest, at isotime, and at the end of exercise. In contrast, there was no change from baseline in EELV at Week 3 with placebo.

Throughout the study, only two patients did not reach $85 \% \mathrm{SpO}_{2}$ during exercise, suggesting that oxygen desaturation was unlikely to be a major contributor to exercise limitation in these patients.

\section{Static lung function and hyperinflation}

After 3 weeks, aclidinium significantly increased trough IC from baseline versus placebo $(\Delta=78 \mathrm{~mL} ; 95 \%$ CI 10,145 ; $\mathrm{p}<0.05$; Table 2). Other parameters of static lung function were also significantly increased from baseline with aclidinium versus placebo (Table 2).

Mean trough FRC, RV, and sGaw were significantly improved from baseline with aclidinium versus placebo at Week 3 (Table 2). The mean change from baseline in trough IC:TLC ratio was 0.016 with aclidinium and 0.002 with placebo $(\Delta=0.014 ; \mathrm{p}<0.01)$. At Week 3, significant improvements from baseline with aclidinium 


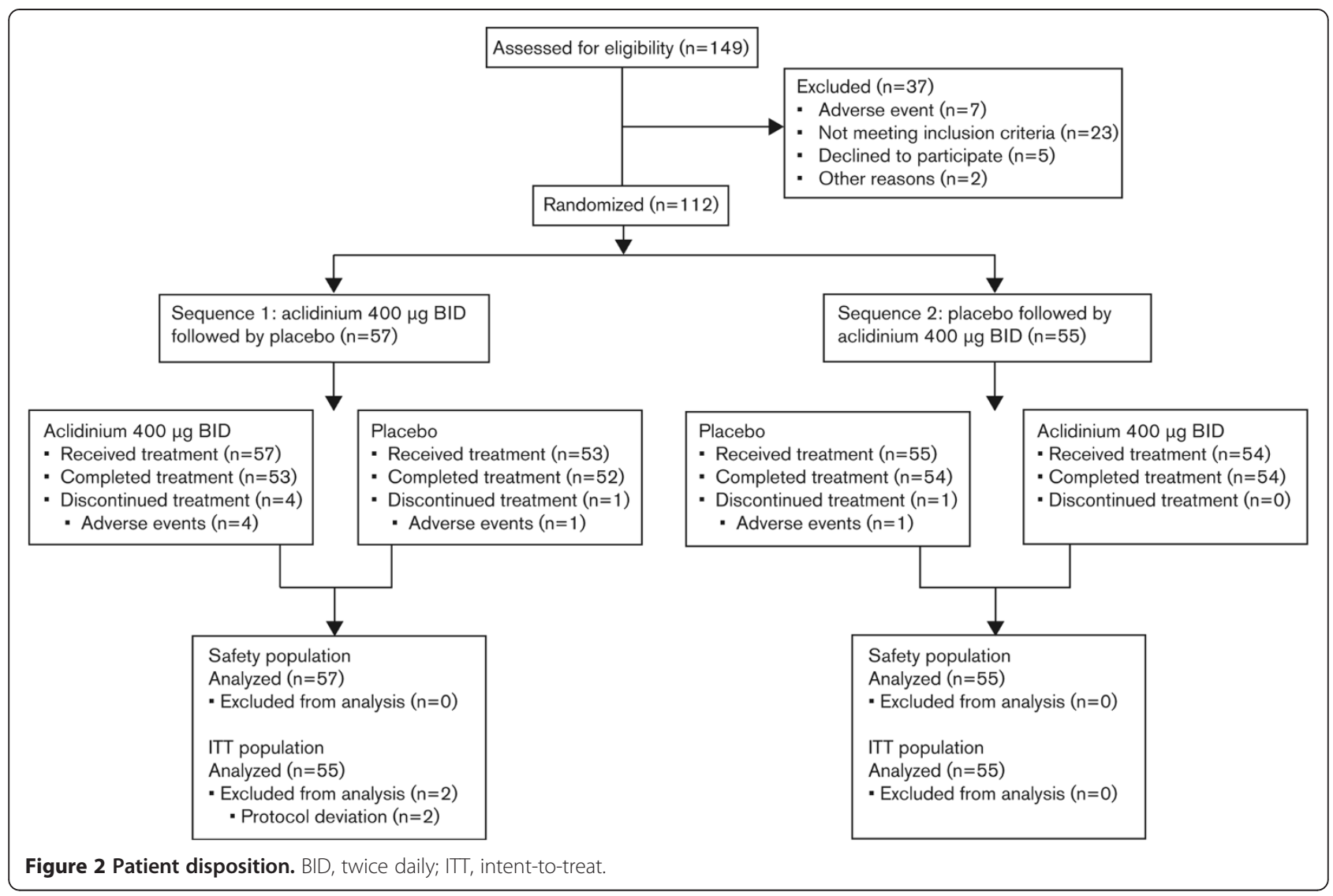

versus placebo were observed for mean post-dose FRC, RV, TLC, and sGaw (Table 2).

When assessed across the placebo and aclidinium treatment periods, there was a weak negative correlation between changes from baseline in endurance time and post-dose RV $(\mathrm{r}=-0.159 ; \mathrm{p}<0.05)$, post-dose FRC $(r=-0.175 ; \mathrm{p}=0.01)$, and trough FRC $(\mathrm{r}=-0.144$; $\mathrm{p}<0.05$ ), and a weak positive correlation between changes from baseline in endurance time and IC at rest $(\mathrm{r}=0.231 ; \mathrm{p}<0.001)$. There was no significant correlation between changes in endurance time and trough RV and trough IC. In the aclidinium treatment period, correlations between lung volumes and endurance time were weak and did not reach statistical significance.

\section{Physical activity and symptoms}

Changes from baseline in physical activity, as measured by duration of activity of at least moderate intensity and daily active energy expenditure, were significantly increased with aclidinium versus placebo at Week 3 (Table 3). Numeric increases in step count and physical activity level were also observed with aclidinium versus placebo but did not reach significance (Table 3).

When assessed across both treatments, there was no significant correlation between changes from baseline in step count or moderate activity and changes from baseline in endurance time (Table 4). Improvements in physical activity parameters were related, and changes from baseline in endurance time were negatively correlated with changes in dyspnea at isotime (Table 4). As shown in Additional file 4, similar results were observed during the aclidinium period only.

Over 3 weeks there was a significant increase in relief medication-free days with aclidinium versus placebo $(6.3 \%$ vs $20.9 \% ; \Delta=14.6 \% ; \mathrm{p}<0.0001)$. Reductions in number of nocturnal awakenings due to COPD symptoms were small and there was no significant difference between treatments $(\mathrm{p}=0.46)$.

\section{Treatment effect by baseline PAL}

Post-hoc analyses assessed change from baseline in endurance time at Week 3 in patients categorized as 'extremely inactive', 'sedentary', and 'at least moderately active' at baseline. Improvements in endurance time with aclidinium compared with placebo were greatest in patients who were categorized as extremely inactive at baseline (Figure 6a). While there were also improvements in endurance time with aclidinium versus placebo in patients who were sedentary at baseline, these improvements were not statistically significant.

When physical activity parameters were assessed, improvements with aclidinium versus placebo were generally 


\section{Characteristic}

Patients $(\mathrm{N}=112)$

Age (years), mean (SD)

$60.3(8.1)$

Gender (male), n (\%)

Race (Caucasian/white), n (\%)

Current smoker, n (\%)

Smoking history (pack-years), mean (SD)

COPD duration (years), mean (SD)

Severity of airflow limitation, $\mathrm{n}(\%)$

Moderate

Severe

Post-bronchodilator $\mathrm{FEV}_{1}(\mathrm{~L})$ at screening

Mean (SD)

$\%$ predicted, mean (SD)

FRC at screening $(\mathrm{L})$

Mean (SD)

$\%$ predicted, mean (SD)

Exercise endurance time at baseline ${ }^{\mathrm{b}}(\mathrm{s})$, mean (SD) $485.7(234.4)$

Intensity of dyspnea at isotime at baseline ${ }^{\mathrm{b}}$ (Borg CR-10 scale), mean (SD)

Lung function variables at baseline, ${ }^{\mathrm{b}}$ mean (SD)

$$
\mathrm{FEV}_{1}(\mathrm{~L})
$$

$\%$ predicted $\mathrm{FEV}_{1}$

FVC (L)

$\%$ predicted FVC

IC (L)

Whole-body plethysmographic variables at baseline, ${ }^{\text {b }}$ mean (SD)

FRC (L)

$\%$ predicted FRC

$\mathrm{RV}(\mathrm{L})$

$\%$ predicted RV

TLC (L)

$\%$ predicted TLC

sGaw $\left(\mathrm{s}^{-1} \mathrm{kPa}^{-1}\right)$

Physical activity variables at baseline, ${ }^{\mathrm{C}}$ mean (SD)

Step count (steps per day)

Duration of activity of at least moderate intensity ${ }^{\mathrm{d}}$ (min/day)

Physical activity level ${ }^{\mathrm{e}}$

Daily active energy expenditure $>3$ metabolic equivalents ( $\mathrm{kcal} / \mathrm{day}$ )

${ }^{a}$ GOLD Stage 2 (moderate): $\mathrm{FEV}_{1} / \mathrm{FVC}<0.70$, and post-bronchodilator $\mathrm{FEV}_{1} \geq 50 \%$ and $<80 \%$ predicted; GOLD Stage 3 (severe): $\mathrm{FEV} / \mathrm{FVC}_{1}<0.70$, and post-bronchodilator FEV $_{1} \geq 30 \%$ and $<50 \%$ predicted.

${ }^{\mathrm{b}}$ Pre-dose at Visit 1.

${ }^{\mathrm{c}}$ Mean data for 7-day period prior to Visit 1 (patients who had $\geq 5$ days with $\geq 22 \mathrm{~h}$ of valid data; $\mathrm{n}=92$ ).

${ }^{d}$ Any physical activity $>3$ metabolic equivalents.

' Ratio calculated as the total daily energy expenditure divided by the whole of the night sleeping energy expenditure.

COPD, chronic obstructive pulmonary disease; $\mathrm{FEV}_{1}$, forced expiratory volume in 1 s; FRC, functional residual capacity; FVC, forced vital capacity; GOLD, Global initiative for chronic Obstructive Lung Disease; IC, inspiratory capacity; RV, residual volume; SD, standard deviation; sGaw, specific airway conductance; TLC, total lung capacity. 


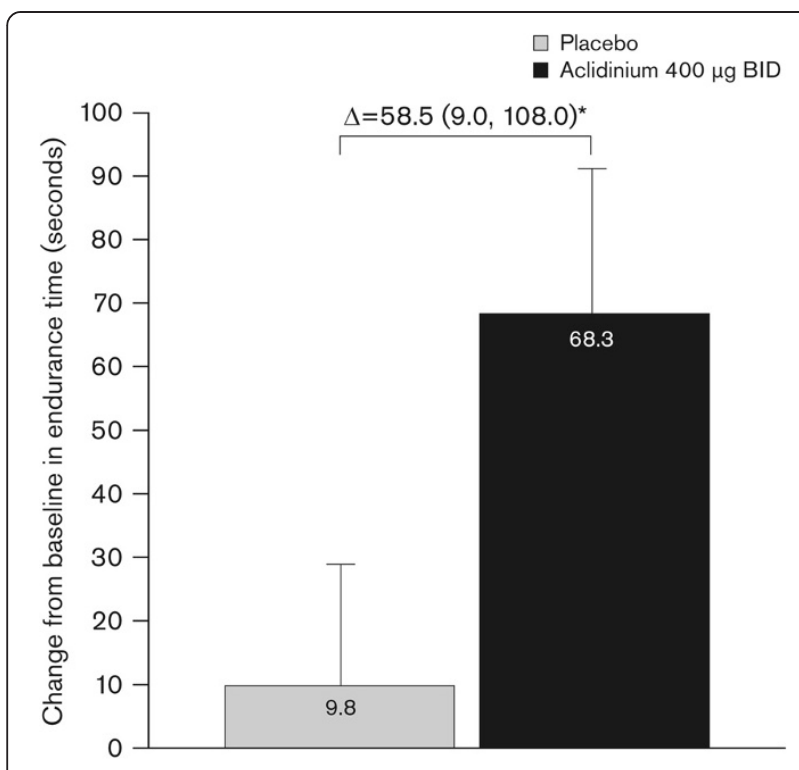

Figure 3 Change from baseline in exercise endurance time at Week 3. Change from baseline in exercise endurance time during constant work rate cycle ergometry to symptom limitation at $75 \%$ of the maximum work rate was assessed at Week 3 (ITT population). Data reported as least squares means change from baseline (analysis of covariance) + standard error; $\Delta=$ least squares means difference ( $95 \%$ confidence interval). ${ }^{*} \mathrm{p}<0.05$ versus placebo. BID, twice daily; ITT, intent-to-treat. greatest in patients who were categorized as sedentary at baseline (Figure 6). In these patients, the improvement in daily step count was significantly greater with aclidinium versus placebo (Figure 6).

\section{Safety}

The incidence of AEs was higher with aclidinium (44.1\%) than with placebo (30.6\%). The most common AEs were nasopharyngitis, headache, and abnormal (bitter) product taste; each reported by a higher proportion of patients receiving aclidinium $(6.3 \%, 4.5 \%$, and $3.6 \%$, respectively) than placebo $(3.7 \%, 2.8 \%$, and $1.9 \%$, respectively). There were few discontinuations due to AEs following aclidinium and placebo (3.6\% and $1.9 \%$, respectively). No serious AEs occurred during treatment with aclidinium. There were no clinically relevant changes in hematology or biochemistry parameters, or in other safety variables.

\section{Discussion}

The results of this study show that after 3 weeks, aclidinium $400 \mu \mathrm{g}$ BID significantly reduced the intensity of exertional dyspnea and improved cycling exercise endurance compared with placebo. As lung hyperinflation is believed to be an important factor contributing to reduced exercise capacity in COPD [5-8], we believe the main driver of increased exercise endurance was the consistent effect of aclidinium treatment on lung volumes, as reflected by significant improvements in static IC, FRC, RV, and TLC, as well as dynamic IC during exercise.

The improvement in endurance time observed with aclidinium was similar to that observed previously with

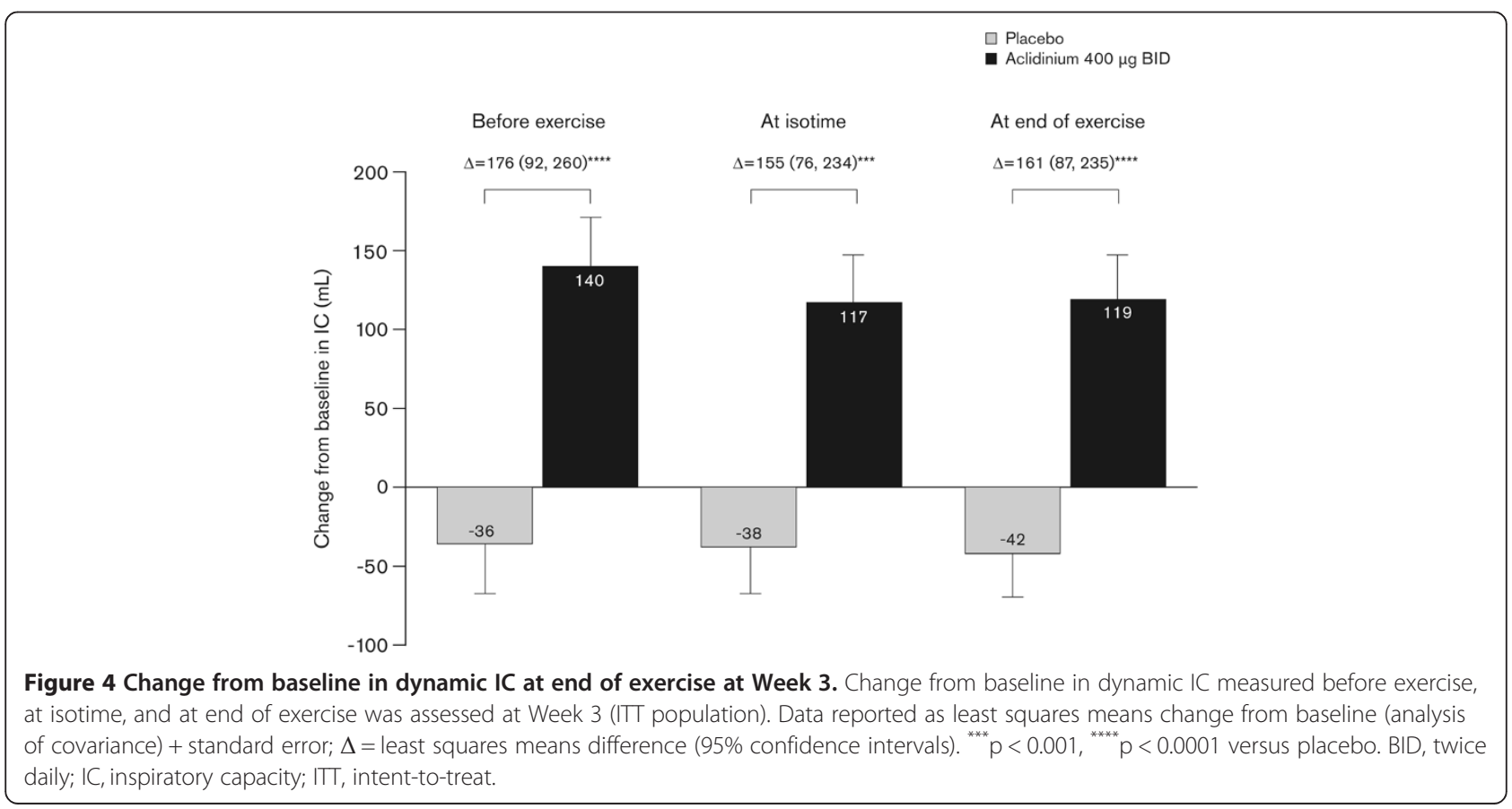




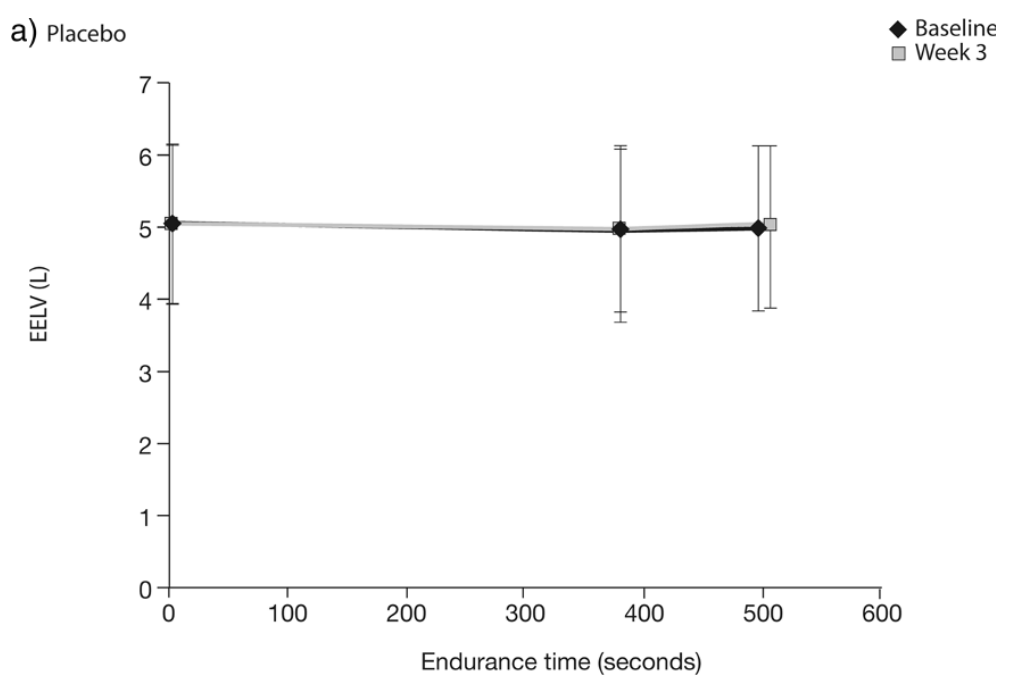

b) Aclidinium $400 \mu \mathrm{g}$ BID

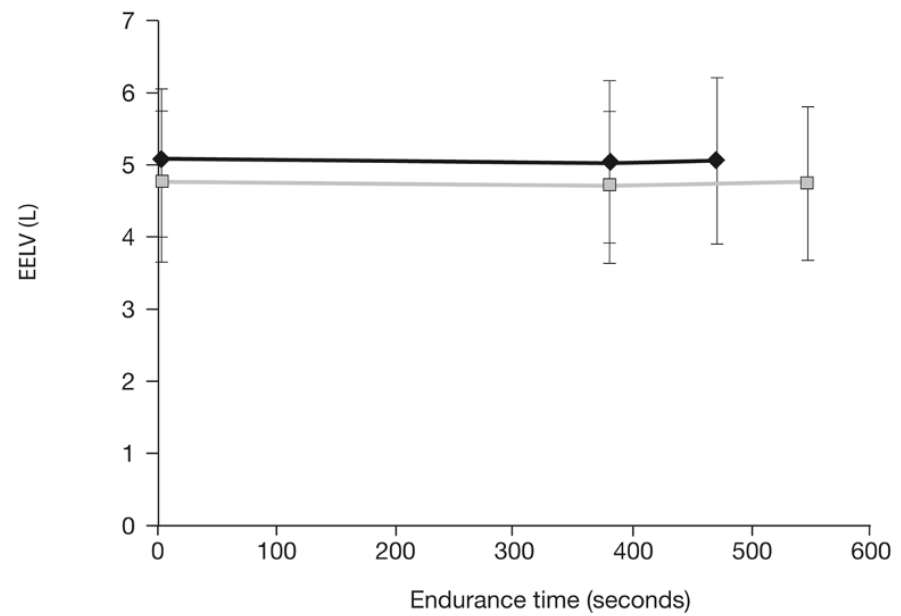

Figure 5 EELV during exercise at baseline and at Week 3. EELV during constant work rate cycle ergometry in patients receiving a) placebo, or b) aclidinium $400 \mu \mathrm{g} \mathrm{BID.} \mathrm{EELV} \mathrm{was} \mathrm{assessed} \mathrm{at} \mathrm{rest,} \mathrm{at} \mathrm{isotime,} \mathrm{and} \mathrm{at} \mathrm{end} \mathrm{of} \mathrm{exercise} \mathrm{at} \mathrm{baseline} \mathrm{and} \mathrm{at} \mathrm{Week} 3$ (ITT population). Data are descriptive and reported as mean \pm standard deviation. EELV was assessed as IC subtracted from mean TLC $2 \mathrm{~h}$ post-dose. Mean isotime was calculated as 386 seconds. BID, twice daily; EELV, end-expiratory lung volumes; IC, inspiratory capacity; ITT, intent-to-treat; TLC, total lung capacity.

tiotropium $18 \mu \mathrm{g}$ QD (67 s) [10], but lower than that seen with glycopyrrolate $50 \mu \mathrm{g}$ QD (89 s) [13]. Improvements, versus placebo, in IC at isotime (a marker of dynamic hyperinflation) were also similar between aclidinium $400 \mu \mathrm{g}$ BID $(155 \mathrm{~mL})$, tiotropium $18 \mu \mathrm{g}$ QD $(180-190 \mathrm{~mL})$ [10,22], and glycopyrrolate $50 \mu \mathrm{g}$ QD $(200 \mathrm{~mL})$ [13]. Furthermore, the improvement in static lung function (IC at rest) with aclidinium $(176 \mathrm{~mL})$ was also comparable to that provided by other LAMAs $(180-220 \mathrm{~mL})[10,13,22]$.

It has been proposed that a minimal clinically important difference for exercise endurance time is in the range 46-105 s [23,24]; however, these estimates are based on few studies and do not take into account the large variation in, for example, interventions, study methodology/ duration, patient characteristics and disease severity, and exercise testing protocols. Furthermore, it is unclear if a change observed with a pulmonary rehabilitation program involving regular training units is comparable to what can be achieved with bronchodilators. Nevertheless, most published improvements in cycling endurance with bronchodilators are in line with the proposed range. We therefore believe that the improvements seen with aclidinium fit well with the published data and indicate a meaningful response.

In the present study, there was a correlation between improvements in endurance time and reduced exertional dyspnea, overall and in the aclidinium treatment period only. Overall, improvements in endurance time were also correlated with reduced post-dose RV and FRC and increased IC at rest. There was no significant correlation 
Table 2 Changes from baseline in lung function and body plethysmography parameters at Week 3 (ITT population)

\begin{tabular}{|c|c|c|c|}
\hline Parameter & Placebo $(\mathrm{N}=108)$ & Aclidinium $400 \mu \mathrm{g}$ BID $(\mathrm{N}=109)$ & Treatment difference vs placebo $(95 \% \mathrm{Cl})$ \\
\hline Pre-dose (trough) IC (mL) & $20(25)$ & $98(24)$ & $78(10,145)^{*}$ \\
\hline Pre-dose (trough) FEV ${ }_{1}(\mathrm{~mL})$ & $-25(21)$ & $108(21)$ & $132(74,191)^{* * * * *}$ \\
\hline Pre-dose (trough) FVC (mL) & $-46(31)$ & $198(30)$ & $243(157,329)^{* * * *}$ \\
\hline \multicolumn{4}{|l|}{$\mathrm{FRC}(\mathrm{mL})$} \\
\hline Pre-dose (trough) & $15(39)$ & $-182(39)$ & $-197(-321,-72)^{* *}$ \\
\hline Post-dose & $-130(46)$ & $-449(46)$ & $-318(-448,-189)^{* * * *}$ \\
\hline \multicolumn{4}{|l|}{$\mathrm{RV}(\mathrm{mL})$} \\
\hline Pre-dose (trough) & $15(60)$ & $-222(60)$ & $-238(-396,-79)^{* *}$ \\
\hline Post-dose & $-81(57)$ & $-523(57)$ & $-443(-599,-286)^{* * * *}$ \\
\hline \multicolumn{4}{|l|}{$\mathrm{TLC}(\mathrm{mL})$} \\
\hline Pre-dose (trough) & $-6(41)$ & $-82(41)$ & $-76(-201,49)$ \\
\hline Post-dose & $-49(41)$ & $-199(41)$ & $-150(-262,-37)^{* *}$ \\
\hline \multicolumn{4}{|l|}{$\mathrm{sGaw}\left(\mathrm{s}^{-1} \mathrm{kPa}^{-1}\right)$} \\
\hline Pre-dose (trough) & $0.002(0.020)$ & $0.096(0.020)$ & $0.094(0.038,0.150)^{* *}$ \\
\hline Post-dose & $0.054(0.027)$ & $0.297(0.026)$ & $0.243(0.182,0.303)^{* * * *}$ \\
\hline
\end{tabular}

Data reported as least squares means (standard error) change from baseline (analysis of covariance).

$\mathrm{p}<0.05,{ }^{* *} \mathrm{p}<0.01,{ }^{* * * *} \mathrm{p}<0.0001$ versus placebo.

$\mathrm{BID}$, twice daily; $\mathrm{Cl}$, confidence interval; $\mathrm{FEV}_{1}$, forced expiratory volume in 1 s; FRC, functional residual capacity; FVC, forced vital capacity; IC, inspiratory capacity; $\mathrm{ITT}$, intent-to-treat; RV, residual volume; sGaw, specific airway conductance; TLC, total lung capacity.

between changes from baseline in static lung volumes and endurance time when assessed in the aclidinium treatment period only. To the best of our knowledge, only one previous study has investigated the relationship between exercise endurance time and lung volumes following treatment with a LAMA in patients with COPD [10]. While a correlation between endurance time and exertional dyspnea and between endurance time and dynamic IC was observed following treatment with tiotropium $18 \mu \mathrm{g}$; the relationship between endurance time and static lung volumes was not reported [10]. Furthermore, patients were treated with tiotropium $18 \mu \mathrm{g}$ for 6 weeks compared with the shorter 3-week treatment period with aclidinium in the present study.

Aclidinium treatment also significantly improved the duration of activity of moderate intensity and daily energy expenditure. It is difficult to speculate on the clinical relevance of the improvement in the duration of moderate physical activity observed with aclidinium (10 min vs placebo). Recently, a prospective cohort study reported the health benefits of 15 min moderate physical activity per day in terms of mortality reduction in the general population [25]. Furthermore, physical activity level has been found to be a strong predictor of mortality in patients with COPD [26,27]. Further studies are needed to link improvements in physical activity in COPD to other patientcentered outcomes, and ideally, to also demonstrate health benefits in terms of reduced morbidity and mortality.

In the present study, there was no correlation between improved endurance time and increased physical activity in the whole study population and following treatment with aclidinium. This might be based on the observation

Table 3 Changes from baseline in physical activity parameters at Week 3 (ITT population)

\begin{tabular}{|c|c|c|c|}
\hline Parameter & $\begin{array}{l}\text { Placebo } \\
\left(n=83^{a}\right)\end{array}$ & $\begin{array}{l}\text { Aclidinium } 400 \mu \mathrm{g} \text { BID } \\
\qquad\left(\mathrm{n}=85^{\mathrm{a}}\right)\end{array}$ & $\begin{array}{l}\text { Treatment difference vs placebo } \\
(95 \% \mathrm{Cl})\end{array}$ \\
\hline Step count (steps per day) & $-163.2(226.1)$ & $295.8(223.7)$ & $459.0(-61.8,979.8)$ \\
\hline Duration of activity of at least moderate intensity ${ }^{b}$ (min/day) & $-5.9(4.1)$ & $4.2(4.1)$ & $10.1(2.0,18.2)^{*}$ \\
\hline Physical activity level ${ }^{c}$ & $-0.006(0.013)$ & $0.018(0.013)^{d}$ & $0.024(-0.003,0.051)$ \\
\hline Daily active energy expenditure $>3$ metabolic equivalents (kcal/day) & $-32.7(21.0)$ & $21.9(20.8)$ & $54.5(13.3,95.8)^{*}$ \\
\hline
\end{tabular}

Data reported as least squares means (standard error) change from baseline (analysis of covariance). ${ }^{*} \mathrm{p}<0.05$ versus placebo.

${ }^{a} n=$ number of patients who had $\geq 5$ days with $\geq 22 \mathrm{~h}$ of valid data and were included in the analyses.

${ }^{\mathrm{b}}$ Any physical activity $>3$ metabolic equivalents.

${ }^{\mathrm{C}}$ Ratio calculated as the total daily energy expenditure divided by the whole of the night sleeping energy expenditure.

${ }^{\mathrm{d}} \mathrm{n}=84$.

$\mathrm{BID}$, twice daily; $\mathrm{Cl}$, confidence interval; ITT, intent-to-treat. 
Table 4 Relationship between physical activity, endurance time, and exertional dyspnea

\begin{tabular}{|c|c|c|c|c|}
\hline & & Observations $^{a}$ & Correlation & P-value \\
\hline \multirow[t]{2}{*}{ Change from baseline in daily step count ${ }^{b}$} & Change from baseline in endurance time (s) & 168 & 0.061 & 0.433 \\
\hline & $\begin{array}{l}\text { Change from baseline in duration of at least } \\
\text { moderate activity (min) }\end{array}$ & 168 & 0.640 & $<0.0001$ \\
\hline $\begin{array}{l}\text { Change from baseline in duration of at least } \\
\text { moderate activity }(\mathrm{min} / \text { day) })^{\mathrm{b}}\end{array}$ & Change from baseline in endurance time (s) & 168 & -0.015 & 0.845 \\
\hline Change from baseline in endurance time (s) & Change from baseline in exertional dyspnea at isotime & 216 & -0.535 & $<0.0001$ \\
\hline
\end{tabular}

Pearson correlation for change from baseline in mean daily step count, mean duration of at least moderate activity ( $>3$ metabolic equivalents), endurance time during constant work rate cycle ergometry to symptom limitation at $75 \%$ of the maximum work rate, and exertional dyspnea at isotime across the study

(aclidinium and placebo treatment periods; ITT population).

${ }^{a}$ Number of observations used to calculate the correlation.

${ }^{\mathrm{b}}$ Patients who had $\geq 5$ days with $\geq 22 \mathrm{~h}$ of valid data.

ITT, intent-to-treat.

that patients in this study who were extremely inactive at baseline had the greatest improvements in endurance time, whereas patients who were sedentary at baseline had the greatest improvements in physical activity. While the analyses reported here were exploratory, and in the case of the baseline PAL analyses, performed in small numbers of patients, they expand previous studies that suggest factors other than increased capacity are involved in driving patients with COPD to become more physically active.

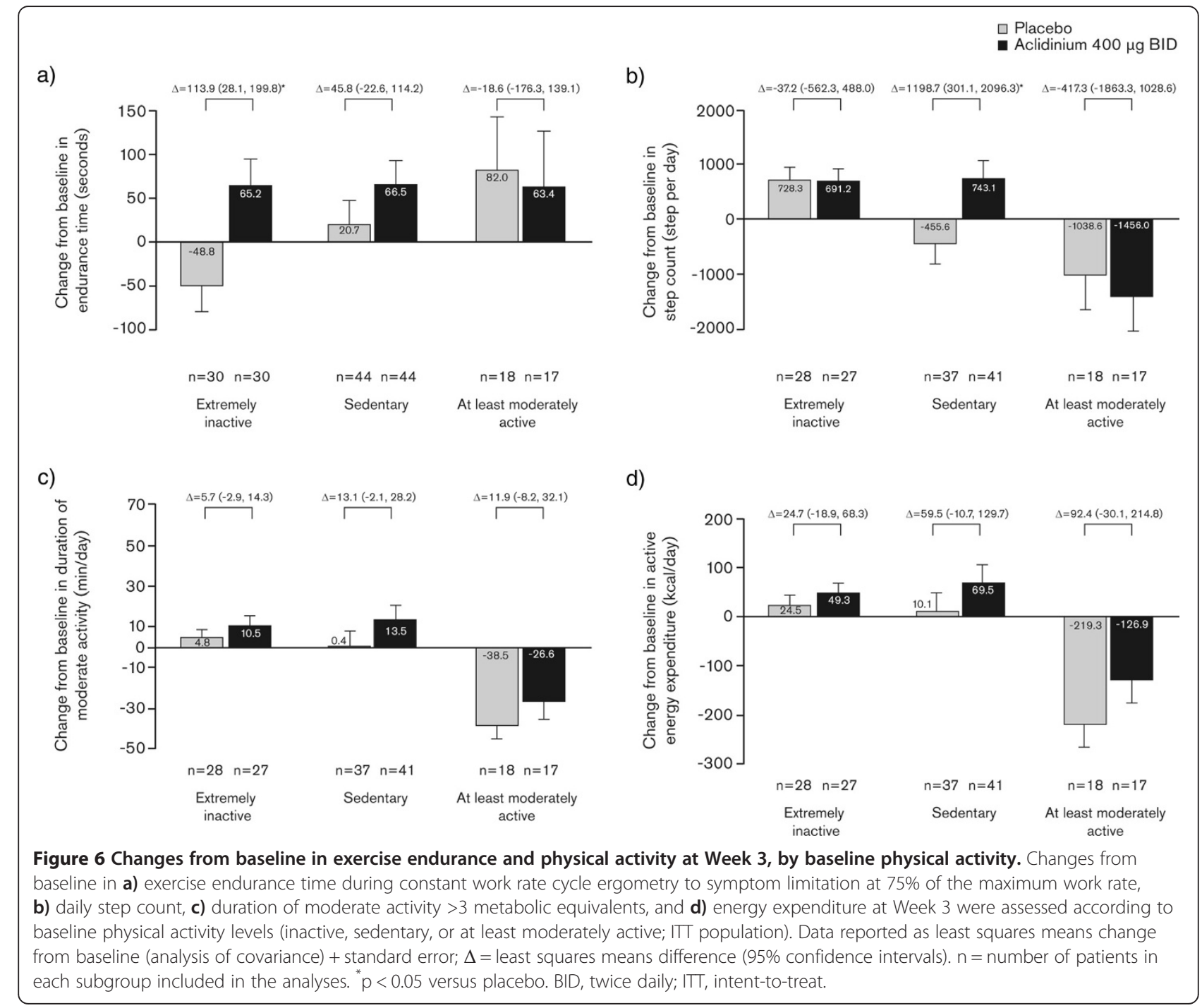


Study limitations might include the short treatment duration, absence of assessments beyond $3 \mathrm{~h}$ post-dose to determine duration of effect, and the lack of an active comparator. Nevertheless, this study provides useful data to supplement findings from previous Phase III studies, demonstrating that aclidinium significantly improved lung function and symptoms versus placebo over 12 and 24 weeks and had comparable 24-h bronchodilatory efficacy to tiotropium over 6 weeks in patients with COPD [28-30]. Aclidinium has also been demonstrated to be safe and well tolerated in patients with COPD $[29,30]$, and the safety findings from this short study were consistent with those previously observed.

\section{Conclusions}

Treatment with aclidinium $400 \mu \mathrm{g}$ BID significantly improved exercise endurance and related exertional dyspnea, and lung hyperinflation compared with placebo over 3 weeks in patients with stable COPD and moderate-to-severe airflow limitation. Aclidinium also provided significant improvements in static lung function and lung volumes, and parameters of physical activity compared with placebo.

\section{Endnote}

${ }^{a}$ Registered trademarks of AstraZeneca PLC, Barcelona, Spain; for use within the USA as Pressair ${ }^{\circ}$, and Genuair ${ }^{\circ}$ within all other licensed territories.

\section{Additional files}

\section{Additional file 1: Institutions and Independent Ethics Committees.}

Details of institutions and Independent Ethics Committees.

Additional file 2: Prior COPD medication use by therapeutic category. Number of patients using any pre-study medication for COPD. Additional file 3: Change from baseline in IC during exercise at Week 3. Changes from baseline in inspiratory capacity every 2 min during exercise (assessed by constant work rate cycle ergometry).

Additional file 4: Relationship between physical activity, endurance time, and exertional dyspnea. Pearson correlation for change from baseline in mean daily step count, mean duration of at least moderate activity ( $>3$ metabolic equivalents), endurance time during constant work rate cycle ergometry to symptom limitation at $75 \%$ of the maximum work rate, and exertional dyspnea at isotime across the study during the aclidinium treatment period only.

\section{Abbreviations \\ AE: Adverse event; BID: Twice daily; Cl: Confidence interval; COPD: Chronic obstructive pulmonary disease; EELV: End-expiratory lung volume; $\mathrm{FEV}_{1}$ : Forced expiratory volume in $1 \mathrm{~s}$; FRC: Functional residual capacity; FVC: Forced vital capacity; IC: Inspiratory capacity; ITT: Intent-to-treat; LABA: Long-acting 32 -agonist; LAMA: Long-acting muscarinic antagonist; PAL: Physical activity level; QD: Once daily; RV: Residual volume; sGaw: specific airway conductance; $\mathrm{SpO}_{2}$ : Oxygen saturation; TLC: Total lung capacity; $\Delta$ : Treatment group difference.}

\section{Competing interests}

Kai $\mathrm{M}$ Beeh has received compensation for organizing or participating in advisory boards for Almirall Hermal, Cytos, Chiesi, Boehringer Ingelheim, AstraZeneca, Mundipharma, Novartis, and Revotar Biopharmaceuticals and participated as a speaker in scientific meetings or courses supported by various pharmaceutical companies (Almirall Hermal, AstraZeneca, Boehringer Ingelheim, Novartis, Pfizer, and Takeda) in the past 3 years. He has received consulting fees from Ablynx, Apellis Pharmaceuticals, Chiesi, and Cytos. The institution where he is employed (insaf Respiratory Research Institute) has received compensation for the design, performance, or participation in single or multicenter clinical trials in the past 3 years from several companies including Almirall, Boehringer Ingelheim, Cytos, GSK, Mundipharma, Novartis, Pfizer, Revotar Biopharmaceuticals, Sterna AG, and TEVA. Henrik Watz is an employee of the Pulmonary Research Institute. His institution received reimbursement from Almirall for the conduct of the study and analysis of the physical activity data. Henrik Watz received speaking honoraries, honoraries for participation in advisory board meetings, travel support for attending congresses in respiratory medicine, and unrestricted research grants from Almirall, BerlinChemie, Boehringer, AstraZeneca, GSK, Merck, Novartis, and Takeda. His institution received compensation for participation in clinical studies from Almirall, AstraZeneca, AB2BIO, Bayer, Boehringer Ingelheim, GSK, Intermune, Merck, Novartis, Revotar, Roche, and Takeda.

Luis Puente-Maestu's institution has been paid by PAREXEL/Almirall-Forrest for performing the per protocol required measurements of some of the patients included in this study. His institution has also received payments from Boehringer Ingelheim and Novartis for performing measurements for clinical trials of bronchodilators during the last 36 months. He has received personal fees and non-financial support from Novartis, Lilly, AstraZeneca, GSK, Chiesi, Boehringer Ingelheim, Almirall, Ferrer, and Takeda. His institution received a grant to support a fellow from BACTEK.

Luis de Teresa has no conflict of interest to disclose.

Diana Jarreta is an employee of AstraZeneca PLC and a former employee of Almirall.

Cynthia Caracta is a former employee of Forest Laboratories LLC, a subsidiary of Actavis, Jersey City, NJ, USA.

Esther Garcia Gil is an employee of AstraZeneca PLC and a former employee of Almirall.

Helgo Magnussen is an employee of the Pulmonary Research Institute. His institution received reimbursement from Almirall for the conduct of the study and analysis of the physical activity data. Helgo Magnussen received speaking honoraries, honoraries for participation in advisory board meetings, travel support for attending congresses in respiratory medicine, and unrestricted research grants from Almirall, Aerocrine, BerlinChemie, Boehringer Ingelheim, AstraZeneca, GSK, Merck, Novartis, and Takeda. His institution received compensation for participation in clinical studies from Almirall, AstraZeneca, AB2BIO, Bayer, Boehringer Ingelheim, GSK, Intermune, Merck, Novartis, Revotar, Roche, and Takeda.

This study was supported by Almirall S.A., Barcelona, Spain, and Forest Laboratories LLC, a subsidiary of Actavis, New York, NY, USA. The study sponsors (Almirall S.A., Barcelona, Spain, and Forest Laboratories LLC, a subsidiary of Actavis, New York, NY, USA) were responsible for the conception and design of the study, collection of the data, and data analysis. The sponsors placed no restrictions on statements made in the final version of the manuscript or on the decision to submit the manuscript for publication.

\section{Authors' contributions}

$\mathrm{KB}$ contributed to the design of the study and to the analysis and interpretation of data, was involved in drafting the manuscript, revised it for intellectual content, and provided final approval to submit. HW contributed to the design of the study and to the analysis and interpretation of data, was involved in drafting the manuscript, revised it for intellectual content, and provided final approval to submit. LP-M contributed to the analysis and interpretation of data, was involved in drafting the manuscript, revised it for intellectual content, and provided final approval to submit. LDT contributed to the analysis and interpretation of data, was involved in drafting the manuscript, revised it for intellectual content, and provided final approval to submit. DJ contributed to the design of the study and to the analysis and interpretation of data, was involved in drafting the manuscript, revised it for intellectual content, and provided final approval to submit. CC contributed to the design of the study and to the analysis and interpretation of data, was involved in drafting the manuscript, revised it for intellectual content, and provided final approval to submit. EGG contributed to the design of the study and to the analysis and interpretation of data, was involved in drafting the manuscript, revised it for intellectual content, and provided final approval to submit. HM contributed to the design of the study and to the analysis 
and interpretation of data, was involved in drafting the manuscript, revised it for intellectual content, and provided final approval to submit.

\section{Author's information}

Diana Jarreta Formerly of Almirall S.A., Barcelona, Spain.

Esther Garcia Gil Formerly of Almirall S.A., Barcelona, Spain.

\section{Acknowledgments}

The authors would like to thank the study investigators at each of the participating centers for their contribution to the study. The authors would also like to thank Deborah McGregor, PhD, of Complete Medical Communications (Macclesfield, UK), who provided medical writing support under the direction of the authors, funded by Almirall S.A., Barcelona, Spain. Statistical analyses were performed by Marie Pierre Malice of Almirall.

\section{Author details}

${ }^{1}$ insaf Respiratory Research Institute, Wiesbaden, Germany. ${ }^{2}$ Pulmonary Research Institute at LungClinic Grosshansdorf, Airway Research Centre North, German Centre for Lung Research, Woehrendamm 80, D-22927 Grosshansdorf, Germany. ${ }^{3}$ Hospital General Universitario Gregorio Marañón-Universidad Complutense, Madrid, Spain. ${ }^{4}$ Hospital de San Vicente, Alicante, Spain. ${ }^{5}$ AstraZeneca PLC, Barcelona, Spain. ${ }^{6}$ Formerly of Forest Research Institute, Forest Laboratories LLC, a subsidiary of Actavis, Jersey City, NJ, USA

Received: 27 June 2014 Accepted: 11 December 2014

Published: 23 December 2014

\section{References}

1. Arne M, Lundin F, Boman G, Janson C, Janson S, Emtner M: Factors associated with good self-rated health and quality of life in subjects with self-reported COPD. Int J Chron Obstruct Pulmon Dis 2011, 6:511-519.

2. Eisner MD, Iribarren C, Yelin EH, Sidney S, Katz PP, Ackerson L, Lathon $\mathrm{P}$ Tolstykh I, Omachi T, Byl N, Blanc PD: Pulmonary function and the risk of functional limitation in chronic obstructive pulmonary disease. Am J Epidemiol 2008, 167:1090-1101.

3. Esteban C, Quintana JM, Aburto M, Moraza J, Equrrola M, Pérez-Izquierdo J, Aizpiri S, Aguirre U, Capelastegui A: Impact of changes in physical activity on health-related quality of life among patients with COPD. Eur Respir J 2010, 36:292-300.

4. Jones PW: Activity limitation and quality of life in COPD. COPD 2007, 4:273-278.

5. O'Donnell DE, Laveneziana P: Dyspnea and activity limitation in COPD: mechanical factors. COPD 2007, 4:225-236.

6. Thomas M, Decramer M, O'Donnell DE: No room to breathe: the importance of lung hyperinflation in COPD. Prim Care Respir J 2013, 22:101-111.

7. Cooper CB: The connection between chronic obstructive pulmonary disease symptoms and hyperinflation and its impact on exercise and function. Am J Med 2006, 119:21-31.

8. Puente-Maestu L, de García PJ, Martínez-Abad Y, Ruíz de Oña JM, Llorente D, Cubillo JM: Dyspnea, ventilatory pattern, and changes in dynamic hyperinflation related to the intensity of constant work rate exercise in COPD. Chest 2005, 128:651-656.

9. Vestbo J, Hurd SS, Agusti AG, Jones PW, Vogelmeier C, Anzueto A, Fabbri LM Martinez FJ, Nishimura M, Stockley RA, Sin DD, Rodriguez-Roisin R: Global strategy for the diagnosis, management, and prevention of chronic obstructive pulmonary disease: GOLD executive summary. Am J Respir Crit Care Med 2013, 187:347-365.

10. O'Donnell DE, Flüge T, Gerken F, Hamilton A, Webb K, Aguilaniu B, Make B, Magnussen $\mathrm{H}$ : Effects of tiotropium on lung hyperinflation, dyspnoea and exercise tolerance in COPD. Eur Respir J 2004, 23:832-840.

11. O'Donnell DE, Casaburi R, Vincken W, Puente-Maestu L, Swales J, Lawrence D, Kramer B: Effect of indacaterol on exercise endurance and lung hyperinflation in COPD. Respir Med 2011, 105:1030-1036.

12. Casaburi R: Factors determining constant work rate exercise tolerance in COPD and their role in dictating the minimal clinically important difference in response to interventions. COPD 2005, 2:131-136.

13. Beeh KM, Singh D, Di Scala L, Drollmann A: Once-daily NVA237 improves exercise tolerance from the first dose in patients with COPD: the GLOW3 trial. Int J Chron Obstruct Pulmon Dis 2012, 7:503-513.
14. Food and Drug Administration: Tudorza ${ }^{\circledast}$ Pressair $^{\circledast}$ (aclidinium bromide). [http://www.accessdata.fda.gov/scripts/cder/drugsatfda/index.cfm? fuseaction=Search.DrugDetails]

15. European Medicines Agency: Eklira ${ }^{\circledast}$ Genuair $^{\circledast}$ (aclidinium bromide). [http:// www.ema.europa.eu/ema/index.jsp?curl=pages/medicines/human/ medicines/002211/human_med_001571.jsp\&mid=WC0b01ac058001d124]

16. Maltais F, Celli B, Casaburi R, Porszasz J, Jarreta D, Seoane B, Caracta C: Aclidinium bromide improves exercise endurance and lung hyperinflation in patients with moderate to severe COPD. Respir Med 2011, 105:580-587.

17. ATS/ACCP: Statement on cardiopulmonary exercise testing. Am J Respir Crit Care Med 2003, 167:211-277.

18. Wanger J, Clausen JL, Coates A, Pedersen OF, Brusasco V, Burgos F, Casaburi R, Crapo R, Enright P, van der Grinten CP, Gustafsson P, Hankinson J, Jensen $R$, Johnson D, Maclntyre N, McKay R, Miller MR, Navajas D, Pellegrino R, Viegi G: Standardisation of the measurement of lung volumes. Eur Respir J 2005, 26:511-522.

19. Miller MR, Hankinson J, Brusasco V, Burgos F, Casaburi R, Coates A, Crapo R, Enright $P$, van der Grinten $C P$, Gustafsson P, Jensen R, Johnson DC Maclntyre N, McKay R, Navajas D, Pedersen OF, Pellegrino R, Viegi G, Wanger J: Standardisation of spirometry. Eur Respir J 2005, 26:319-338.

20. Watz H, Waschki B, Meyer T, Magnussen H: Physical activity in patients with COPD. Eur Respir J 2009, 33:262-272.

21. Guenette JA, Webb KA, O'Donnell DE: Does dynamic hyperinflation contribute to dyspnoea during exercise in patients with COPD? Eur Respir J 2012, 40:322-329.

22. Beeh KM, Korn S, Beier J, Jadayel D, Henley M, D'Andrea P, Banerji D: Effect of QVA149 on lung volumes and exercise tolerance in COPD patients: the BRIGHT study. Respir Med 2014, 108:584-592.

23. Puente-Maestu L, Villar F, de Miguel J, Stringer WW, Sanz P, Sanz ML, García de Pedro J, Martínez-Abad Y: Clinical relevance of constant power exercise duration changes in COPD. Eur Respir J 2009, 34:340-345.

24. Cazzola M, MacNee W, Martinez FJ, Rabe KF, Franciosi LG, Barnes PJ, Brusasco V, Burge PS, Calverley PM, Celli BR, Jones PW, Mahler DA, Make B, Miravitlles M, Page CP, Palange P, Parr D, Pistolesi M, Rennard SI, Rutten-van Mölken MP, Stockley R, Sullivan SD, Wedzicha JA, Wouters EF: Outcomes for COPD pharmacological trials: from lung function to biomarkers. Eur Respir J 2008, 31:416-468.

25. Wen CP, Wai JP, Tsai MK, Yang YC, Cheng TY, Lee MC, Chan HT, Tsao CK, Tsai SP, Wu X: Minimum amount of physical activity for reduced mortality and extended life expectancy: a prospective cohort study. Lancet 2011, 378:1244-1253.

26. Waschki B, Kirsten A, Holz O, Muller KC, Meyer T, Watz H, Magnussen H: Physical activity is the strongest predictor of all-cause mortality in patients with COPD: a prospective cohort study. Chest 2011, 140:331-342.

27. Garcia-Rio F, Rojo B, Casitas R, Lores V, Madero R, Romero D, Galera R, Villasante $C$ : Prognostic value of the objective measurement of daily physical activity in patients with COPD. Chest 2012, 142:338-346.

28. Beier J, Kirsten AM, Mróz R, Segarra R, Chuecos F, Caracta C, Garcia Gil E: Efficacy and safety of aclidinium bromide compared with placebo and tiotropium in patients with moderate-to-severe chronic obstructive pulmonary disease: results from a 6-week, randomized, controlled Phase Illb study. COPD 2013, 10:511-522.

29. Jones PW, Singh D, Bateman ED, Agusti A, Lamarca R, de Miquel G, Segarra R, Caracta C, Garcia Gil E: Efficacy and safety of twice-daily aclidinium bromide in COPD patients: the ATTAIN study. Eur Respir J 2012, 40:830-836.

30. Kerwin EM, D'Urzo AD, Gelb AF, Lakkis H, Garcia Gil E, Caracta CF, ACCORD I study investigators: Efficacy and safety of a 12-week treatment with twice-daily aclidinium bromide in COPD patients (ACCORD COPD I). COPD 2012, 9:90-101.

\section{doi:10.1186/1471-2466-14-209}

Cite this article as: Beeh et al:: Aclidinium improves exercise endurance, dyspnea, lung hyperinflation, and physical activity in patients with COPD: randomized, placebo-controlled, crossover trial. BMC Pulmonary Medicine 2014 14:209. 